\title{
Percutaneous balloon valvotomy in tricuspid stenosis
}

\author{
MUAYED AL ZAIBAG, PAULO RIBEIRO, SAAD AL KASAB \\ From the Adult Cardiology Division, Riyadh Cardiac Centre, Kingdom of Saudi Arabia
}

SUMMARY This report describes the first successful treatment of tricuspid stenosis by percutaneous double balloon valvotomy. There was a dramatic reduction of the tricuspid valve gradient, with an increase in calculated valve area, together with an increase in resting cardiac output and symptomatic relief. The feasibility of the non-surgical treatment of severe tricuspid stenosis was demonstrated unequivocally.

Non-surgical balloon valvotomy has become an established treatment for pulmonary stenosis, ${ }^{1}$ and the technique is currently being assessed for the treatment of aortic and mitral stenosis. ${ }^{23} \mathrm{~A}$ single balloon was used in these studies; however, we have recently reported the advantages of a double balloon technique for mitral valvotomy. ${ }^{4}$

We report the first successful treatment of tricuspid stenosis by percutaneous double balloon valvotomy. This case was selected for this treatment because of the unusual combination of severe rheumatic tricuspid stenosis, with only trivial incompetence, and mild mitral stenosis.

\section{Case report}

A 45 year old labourer with a history of rheumatic fever presented with fatigue that limited his capacity to work and mild exertional dyspnoea. Examination showed sinus rhythm and a prominent " $a$ " wave in the jugular venous pulse. Blood pressure was $130 / 85$ $\mathrm{mmHg}$. The cardiac impulse was normal. A diastolic thrill and murmur at the lower left sternal edge radiated to the apex; there was presystolic and inspiratory accentuation. The electrocardiogram showed biatrial enlargement with a right atrial vector of $0.4 \mathrm{mV}$ and no evidence of right ventricular hypertrophy. The chest $x$ ray was unremarkable.

Rheumatic tricuspid stenosis was confirmed by cross sectional echocardiography which showed thickening and doming of all three leaflets. Before cardiac catheterisation the patient was treated with digoxin and propranolol. Cardiac output was calculated by the thermodilution technique. The mitral

Requests for reprints to Dr Muayed Al Zaibag, Adult Cardiology Division, Riyadh Cardiac Centre, Riyadh Military Hospital, PO Box 7897, Riyadh 11159, Kingdom of Saudi Arabia. and tricuspid gradients were calculated by planimetry and valve areas by the Gorlin formula. Angiographically there was a thickened and domed tricuspid valve with trivial incompetence. The haemodynamic findings indicated severe tricuspid stenosis (fig 1 and table). There was mild mitral stenosis; the valve area was $2 \cdot 0 \mathrm{~cm}^{2}$

\section{Technique of tricuspid double balloon valvotomy}

Informed consent was obtained. Ten $\mathrm{mg}$ of diazepam was given orally as premedication and propranolol was continued. An 18 gauge cannula was inserted into the right femoral artery for pressure monitoring. A 7 French Berman angiocatheter was passed from each femoral vein to measure the pressure gradient across the tricuspid valve and to perform a right ventricular angiogram before and after balloon inflation. After calibration and the recording of identical simultaneous right atrial pressure tracings from both catheters, one catheter was advanced to the right ventricular cavity. Ten consecutive cardiac cycles were recorded at a paper speed of $100 \mathrm{~mm} / \mathrm{s}$ to measure the gradient across the tricuspid valve. The mean tricuspid gradient was only accepted after two identical simultaneous right atrial pressure traces had been recorded after the withdrawal of the right ventricular catheter back into the right atrium.

The 0.038 inch Teflon coated exchange guide wires $(250 \mathrm{~cm}$ long) with curved tips were advanced through two 7 French pigtail catheters, which previously had been inserted percutaneously in each femoral vein. The curved end of each wire was positioned at the apex of the right ventricle (fig 2). A 9 French balloon catheter (Meditech; $15 \mathrm{~mm}$ diameter, $3 \mathrm{~cm}$ length) was advanced percutaneously 

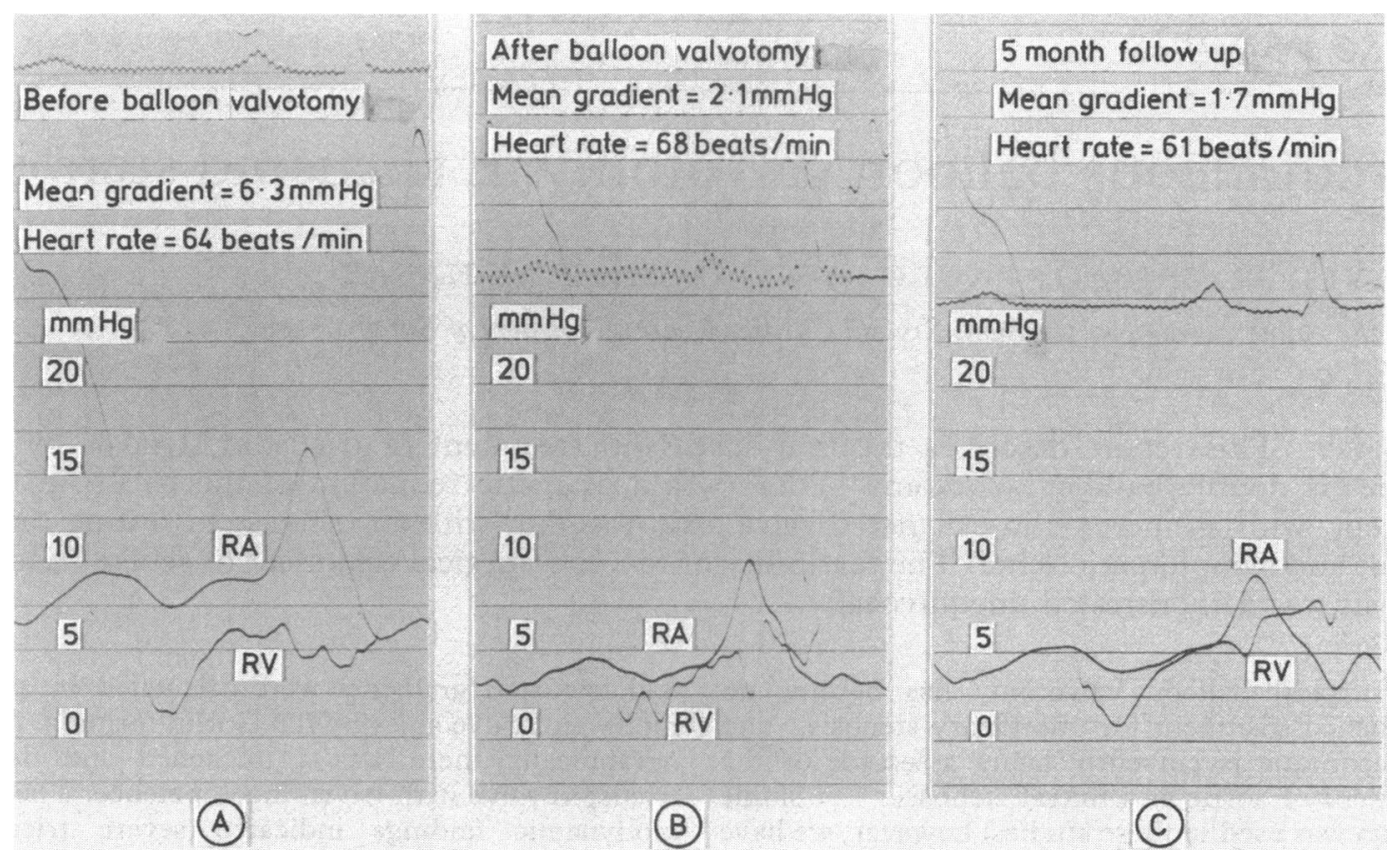

Fig 1 Right atrial $(R A) /$ right ventricular $(R V)$ pressure gradient recording before $(A)$, immediately after $(B)$, and five months after $(C)$ successful balloon tricuspid valvotomy. Note the reduction in the gradient and " $a$ " wave amplitude.

over each guide wire and positioned across the tricuspid valve under fluoroscopic control in the $10^{\circ}$ right anterior oblique projection. The balloons were correctly positioned across the tricuspid valve with the aid of injections of contrast media into the right atrium, and the positioning was confirmed by fluoroscopic detection of the indentation of the balloon during inflation. The balloons were inflated simultaneously on three occasions to a maximum pressure of 5 atmospheres $\left(505 \mathrm{kN} / \mathrm{m}^{2}\right)$. There was no reduction in the tricuspid gradient and no balloon indentation occurred during these inflations. Therefore, we replaced one of the $15 \mathrm{~mm}$ diameter balloon catheters with a $20 \mathrm{~mm}$ diameter balloon that was slid over the exchange guide wire which was left in position. The balloons were inflated three

Table Haemodynamic findings before balloon tricuspid valvotomy $(A)$, immediately after $(B)$, and at 5 month follow up (C)

\begin{tabular}{lccc}
\hline Variable & $A$ & $B$ & $C$ \\
\hline Heart rate/min & 64 & 68 & 61 \\
Cardiac index $\left(1 / \mathrm{min} / \mathrm{m}^{2}\right)$ & $2 \cdot 1$ & $2 \cdot 3$ & 2.8 \\
Pre "a" wave gradient $\left(\mathrm{mm} \mathrm{Hg}^{\mathrm{H}}\right)$ & 3.0 & 0.0 & 0.0 \\
Mean gradient $(\mathrm{mm} \mathrm{Hg})$ & 6.3 & 2.1 & $1 \cdot 7$ \\
Valve area (Gorlin) $\left(\mathrm{cm}^{2}\right)$ & 0.9 & 2.0 & 2.3 \\
\hline
\end{tabular}

more times. During the third inflation proper bal loon alignment was achieved, with indentation of one balloon (fig 2). Disappearance of this indentation, together with the subsequent considerable reduction in the gradient, was taken to indicate successful result.

All inflations lasted for 8-12 s, and during this time the systolic systemic arterial pressure remaine $>80 \mathrm{~mm} \mathrm{Hg}$.

\section{Results}

There was a considerable improvement in hae $\rightarrow$ modynamic variables immediately after balloon tri․ㅡㄹ. cuspid valvotomy (table). At five month follow up while the patient was still taking propranolol to maintain a similar heart rate, the haemodynamic improvement persisted. Biplanar right ventricuks ography showed no increase in tricuspid reguro gitation. The patient reported virtually norm 4 effort tolerance and he had returned to his previou job. At clinical examination we found that the thrill and the long diastolic rumble had disappeared.

\section{Discussion}

This report illustrates the feasibility of percutaneous 

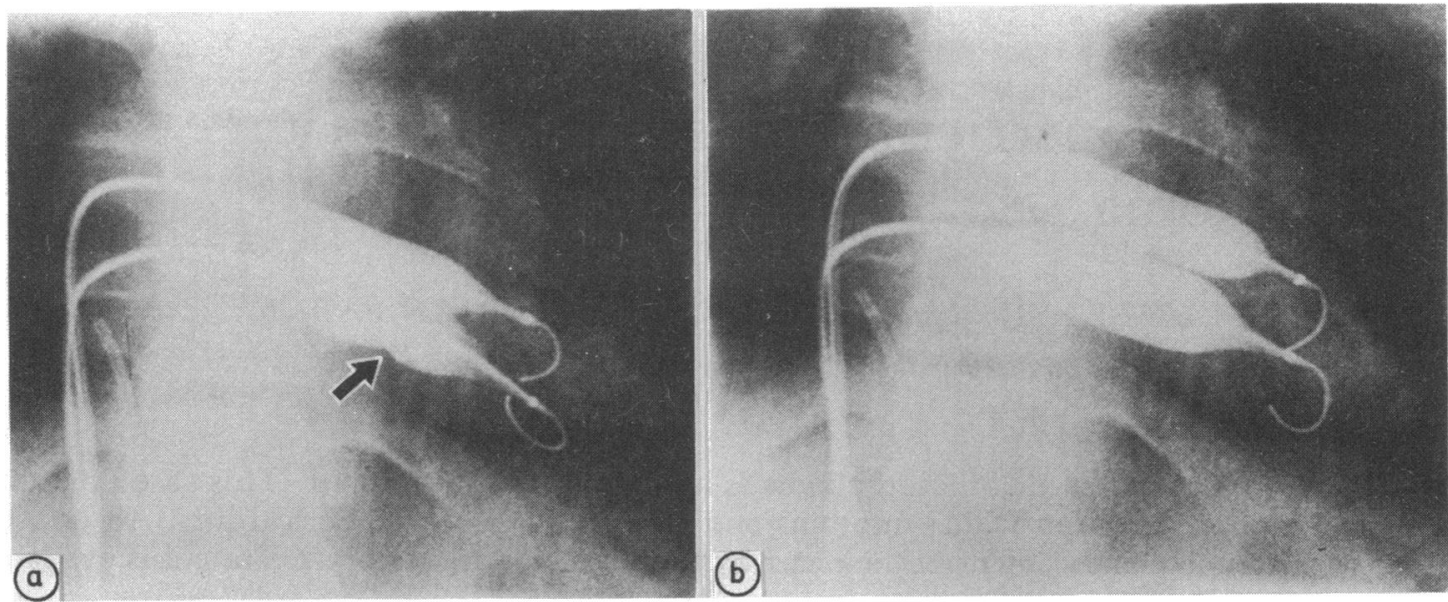

Fig 2 Two balloons positioned across the tricuspid valve. (a) Balloon indentation (arrow) during early inflation.

(b) Loss of balloon indentation after successful double balloon tricuspid valvotomy.

balloon valvotomy of the stenotic tricuspid valve. With the double balloon technique we achieved a considerable reduction in tricuspid valve gradient together with an increase in valve area, without inducing further tricuspid regurgitation. Precise measurement of small pressure gradients is required for the haemodynamic diagnosis of tricuspid valve stenosis. ${ }^{5}$ Hence our strict technique for the gradient measurement includes a second set of simultaneous right atrial pressure recordings, to ensure accuracy by establishing that no calibration drift has occurred, and the maintenance of a relatively constant heart rate with propranolol.

Because of the size of the tricuspid valve, a double balloon technique was required. Our current experience of 25 successful percutaneous mitral valvotomies $^{4}$ indicated that an adequate systolic blood pressure would be maintained during prolonged balloon inflation with the double balloon technique, and this proved to be so.

Because the thin leaflets of the tricuspid valve are easily damaged we initially used two $15 \mathrm{~mm}$ diameter balloons. These were not successful, however. Successful valvotomy, with the disappearance of indentation, was achieved only when one of the $15 \mathrm{~mm}$ balloons was replaced by a $20 \mathrm{~mm}$ balloon.

Because tricuspid stenosis and mitral stenosis can occur together, and in view of the recent demonstra- tion of successful double balloon mitral valvotomy, ${ }^{4}$ this technique could be applied concurrently to both stenotic valves.

We thank Dr William Sawyer for assistance with preparation of the manuscript and the medical illustration department for their contribution.

\section{References}

1 Kan JS, White RI, Mitchell SE, Gardner TJ. Percutaneous balloon valvuloplasty: a new method for treating congenital pulmonary valve stenosis. $N \mathrm{Engl}$ f Med 1982;307:540-2.

2 Lababidi Z, Jiunn-Ren WU, Walls JT. Percutaneous balloon aortic valvuloplasty: results in 23 patients. Am F Cardiol 1984;53:194-7.

3 Ionue K, Owani T, Nakamura T, Miyamoto N. Clinical application of transvenous mitral commissurotomy by a new balloon catheter. $f$ Thorac Cardiovasc Surg 1984;87:394-402.

4 Al Zaibag M, Ribeiro PA, Al Kasab S, Al Fagih MR. Percutaneous double-balloon mitral valvotomy for rheumatic mitral stenosis. Lancet 1986;i:757-61.

5 Ockene IS. Tricuspid valve disease. In: Dalen JE, Alpert JS, eds. Valvular heart disease. Boston: Little, Brown, 1981:281-328. 